\title{
Intestinal Parasitism, Potable Water Availability and Methods of Sewage Disposal in Three Communities in Benue State, Nigeria: A Survey
}

\author{
${ }^{1}$ G. T. A. Jombo, ${ }^{2}$ D. Z. Egah and ${ }^{3}$ J. T. Akosu \\ ${ }^{1}$ Department of Medical Microbiology and Parasitology, College Medical Sciences, University of Calabar, \\ Calabar, ${ }^{2}$ Department of Medical Microbiology, Faculty of Medical Sciences, University of Jos, Jos, and \\ ${ }^{3}$ Department of Community Health, Jos University Teaching Hospital, Jos, Nigeria \\ Reprint requests to: Dr. G. T. A. Jombo, Department of Medical Microbiology and Parasitology, College \\ Medical Sciences, University of Calabar, P M B 1115 Calabar, Nigeria.E-.mail: jombogodwin@yahoo.com
}

\begin{abstract}
Background: To assess the level of parasite burden in a village community and the predisposing factors. Methods: Two hundred subjects each were recruited from three communities- Tyogbenda, Jato-Aka and Adikpo during an episode of free medical outreach. A simple random sampling method was adopted and a questionnaire was interviewer administered on relevant aspects of basic hygiene such as- sources of water supply, methods of domestic sewage disposal and frequency of hand washing. Stool samples were collected and tested and findings analysed using appropriate statistical methods, $\mathrm{p}$ values $<0.05$ were considered significant.
\end{abstract}

Results: The prevalence of intestinal parasites in Tyogbenda, Jato-Aka and Adikpo communities was found to be $71.5 \%, 65.5 \%$ and $40.5 \%$ respectively.

Ascaris lumbricoides was the commonest parasite in the three centres $(34.5 \%, 28.5 \%$ and $19.0 \%$ respectively for Tyogbenda, Jato-Aka and Adikpo communities). Other parasites identified wereEntamoeba histolytica, Entamoeba coli, Hookworm, Enterobius vermicularis, Strongyloides stercoralis, Schistosoma mansoni and Trichuris trichura. Multiple parasitic infestation was common in the communities where quality of water supply and methods of sewage disposal facilities were below standard.

Conclusion: The prevalence of intestinal parasitism is still high in Nigerian rural communities. The present resolve by the federal ministry of water resources to supply potable water to all Nigerian rural communities should be sustained. Furthermore, a health education program should be properly constituted and integrated into the present primary health care policy for the country.

Key words: Intestinal parasites, portable water, sewage

\section{Résumé}

Introduction : Evaluer le niveau du fardeau du parasite dans une communauté villageoise et des facteurs prédisposants.

Méthodes : Deux cents sujets, individuellement récruités venant de trois communautés : Tyogbenda, Jato-Aka et Adikpo pendant l'épisode d'une activité gratuite et médicale visant à encourager les gens à profiter des avantages sociaux. Une méthode simple d'échantillon au hasard était adoptée et un questinnaire était administré sur des aspects pertinents d'hygiène du base tels que des sources d'alimentation en eau, méthodes domestique du traitement des ordures, et la fréquence de se laver les mains. On a fait un prélevement des fèces et étudies et des résultats analysés à travers l'utilisation des méthodes statistique adéquates. P. Valeurs $<0,05$ était considére important.

Résultats: La fréquence des parasites intestinaux dans les communautés Tyogbenda, Jato-Aka et Adokpo était notée d'être 71,5\%,65,5\% et 40,5\% respectivement. Ascaris lumbricoides était le parasite le plus ordinaire dans les trois centres $(34,5 \%, 28,5 \%$ et 19,0\% respectivement pour des communautés Tyogbenda, Jato-Aka et Adkpo. Des autres parasites identifiés sont : Entamoeba histolytica, Entamoeba cole, Hookworm, Enterobius vermicularis, strongyloides stercoralis schistosome mansoni et trichuris trichura. Infestation parasitique multiple était ordinaire dans des communatés où la qualité des aménagements d'alimentation en eau et méthodes de traitement des ordures sont inférieur.

Conclusion: La fréquence du parasitisme intestinal est encore élevé dans des communautés rurales nigérianes. La décision actuelle du Ministère Fédéral des ressources de l'eau de fournir de l'eau buvable dans toutes les communautés rurales nigérianes devrait être soutenue. Par ailleurs, un programme sur le 
renseignement médical devrait être clairement créé et intergré dans la politique des soins médical primaire actuels pour le pays.

Mots-clés : Parasites intestinaux, de l'eau buvables, traitement des ordures

\section{Introduction}

The World Health Organization (WHO) has estimated that, up to $80 \%$ of all sickness and diseases in the world are caused by inadequate sanitation, polluted water or unavailability of water. 1 As there is a growing concern towards improved provision of primary health care services to every nook and cranny of the country, the issue of intestinal parasites quickly comes to fore. Intestinal parasites still constitute a major issue of public health importance in several communities in Nigeria. ${ }^{2-5}$

Several studies in different parts of Nigeria recorded a high prevalence of intestinal parasites. ${ }^{2-5}$ Several of the researchers have shown a close relationship between sources of water supply, water purification methods and methods of sewage disposal and prevalence of intestinal parasite. ${ }^{4}, 5$ A healthy society is that which is among others not plagued by heavy infections and infestations including intestinal parasites. Such a society will give rise to increased productivity and economic transformation of a group of people or a nation.

Most importantly, from the medical point of view, a society free from intestinal parasites will record a lower morbidity and mortality from other infection. ${ }^{6}$

As the drive towards provision of potable water and improvement in the provision of sewage disposal facilities continues, there is need for a concurrent surveillance so as to know the extent to which success has been achieved. This will no doubt be a guide as to the choice of new policies to be adopted so as to improve on sanitation and health conditions of the society.

This study was designed to ascertain, first, the prevalence of intestinal parasites in three communities, and second, their sources of water supply and methods of sewage disposal.

\section{Materials and Methods}

\section{Study area}

The study was carried out in three communities in Benue state during two different episodes of a free medical outreach organized by Non governmental organizations in December 2004 and April 2005. The three communities in which the study was carried out are Tyogbenda, Jato-Aka and Adikpo.

Tyogbenda is a rural settlement in North East of Konshisha L. G. A. about 30 kilometres outside Gboko town, a major town in the locality. Over $95 \%$ of her inhabitants are subsistent farmers. Their major sources of drinking water are streams and wells. The community has no standard toilets based on WHO prescriptions which list standard toilets as follow: Water closets, Pit latrines with concrete walls and removable cover, Ventilated improved pit (VIP) latrine and Double VIP latrines; but has a larger number of "unhygienic" pit latrines which have the tendency of surface soil and under ground water contamination.

Jato-Aka is a rural settlement located in the central Kwande Local Government Area, about 60 kilometres away from Gboko town. The community previously had a sizable number of well built latrines and bore holes before a political crisis in the area which completely devastated the community infrastructure. At present there are no standard toilets in the community except few "unhygienic" pit latrines. Their sources of water are from wells and streams.

Adikpo, the headquarters of Kwande Local Goverment Area (L. G. A) is located at about 120 kilometres away from Makurdi, the Benue state capital. About $85 \%$ of her inhabitants are peasant farmers while the rest are either traders or civil servants. It is a semi-urban centre with water system and well built pit latrines. Their sources of water supply are tap, bore holes and wells.

\section{Study design}

At each of the respective outreach centres (a clinic in each of the locality was used as base for the study) 200 subjects were recruited in to the study via simple random sampling method with the aid of statistical table of random numbers. A pre-tested structured questionnaire was interviewer administered with components on basic hygiene such as - sources of drinking water, methods of water purification, methods of sewage disposal, frequency and thoroughness of hand washing before and after meals highlighted. Stool samples were collected from each respondent using a special bottle and analysed immediately at the health centres variously used for the outreach program.

Pit latrines which did not meet the WHO specifications as established from the questionnaire were grouped along with trenches and open air defaecation.

Samples were processed using saline and iodine preparations without further concentration. Microscopy was carried out using X5, X10 and rarely X40 where applicable. Ethical approval for the study was duly sought and obtained from the ethical committee of the Benue state ministry of health Makurdi; similarly, consent of each respondent was obtained.

\section{Results}

The prevalence of intestinal parasites in Tyogbenda was $76.5 \%$ (153 out of 200), Jato-Aka $71.0 \%$ (142 out of 200) and that of Adikpo 44.0\% (88 out of 200). 
The commonest parasite encountered in the three communities was Ascaris lumbricoides which accounted for $34.5 \%, 28.5 \%$ and $19.0 \%$ in Tyogbenda, Jato-Aka and Adikpo communities respectively.

Table 1 shows nine different species of parasites encountered in the study. Trichuris trichura was not found in Tyogbenda and Jato-Aka but only in Adikpo $(0.5 \%, \mathrm{n}=1)$. Strongyloides stercoralis on the other hand was not found in both Jato-Aka and Adikpo but only in Tyogbenda $(1 \%, \mathrm{n}=2)$. Other parasites encountered in the study were Enterobius vermicularis, Taenia species, Hookworm, Entamoeba histolytica and Entamoeba coli, and Shistosoma mansoni. These parasites recorded various prevalence in the different centres of study with significantly lower prevalence in Adikpo town.

Table 2 shows the number of species of parasites per stool sample in the three communities. Sixty eight percent $(n=136)$ of the people in Tyogbenda had only one species of parasite in their stool, $3 \%(n=6)$ had two and $0.5 \%(\mathrm{n}=1)$ had three species of parasites in their stool. In Jato-Aka, 60\% $(n=120)$ of the respondents had only one parasite in their stool sample, $4.5 \%(n=9)$ had two and $1 \%(n=2)$ had three parasites in their stool samples. All the 81 positive stool samples from Adikpo town had only one species of parasite $(100 \%)$.

Table 3 shows the domestic methods of sewage disposal alongside sources of water supply to Tyogbenda, Jato-Aka and Adikpo communities. Thirty six point five percent $(n=73)$ of the respondents in Tyogbenda had access to water systems or pit latrines, while $63.5 \%(n=127)$ engaged in open air defaecation or the use of trenches. All the respondents' $(100 \%, \mathrm{n}=200)$ sources of water supply was from wells and streams. In Jato-Aka, 30.5\% ( $=$ 61) of the respondents had either water systems or pit latrines, while $69.5 \%(n=139)$ engaged in open air defaecation or use of trenches. Thirteen point five percent $(n=37)$ had access to pipe borne water or bore holes, and $81.5 \% \quad(n=163)$ of the respondents obtained their water from wells and streams.

In Adikpo town, $70.5 \% \quad(n=141)$ of the respondents had access to water systems or pit latrines while $19.5 \% \quad(n=59)$ engaged in either open air defaecation or the use of trenches. Bore holes or pipe borne water was accessible to $68.5 \%(n=137)$ of the respondents while $31.5 \%(n=63)$ of them obtained their water either from wells or streams. The association between methods of sewage disposal, sources of water supply and respectively the prevalence of intestinal parasites was found to statistically significant $(\mathrm{p}<0.0001)$.

Table 4 shows a comparison between frequent hand washing and prevalence of intestinal parasites in the communities under study. Fifty three point five percent $(n=107)$ of the respondent washed hands regularly before and after meals in Tyogbenda, $49 \%$ $(n=98)$ in Jato-Aka and $86.5 \%(n=173)$ in Adikpo. With the corresponding prevalence of intestinal parasites put at $76.5 \%, 71.0 \%$ and $44.0 \%$ respectively, the association between these two factors was found to be statistically significant, $(\mathrm{p}<0.0001)$.

Table 1: Prevalence of involved parasites in Tyogbenda, Ijato-Aka and Adikpo communities

\begin{tabular}{llll}
\hline Parasites & Prevalence & & \\
\hline & Tyogbenda, $\mathrm{n}=200$ & Jato-Aka, $\mathrm{n}=200$ & Adikpo, $\mathrm{n}=200$ \\
& No. positive $(\%)$ & No. positive $(\%)$ & No. Positive $(\%)$ \\
\cline { 2 - 4 } Enterobius vermicularis & $13(6.5)$ & $8(4.0)$ & $5(2.5)$ \\
Ascaris lumbricoides & $69(34.5)$ & $57(28.5)$ & $38(19.0)$ \\
Taenia species & $17(8.5)$ & $19(9.5)$ & $9(4.5)$ \\
Hookworm & $9(4.5)$ & $9(4.5)$ & $13(6.5)$ \\
Entamoeba histolytica & $13(6.5)$ & $17(8.5)$ & $16(8.0)$ \\
Entamoeba coli & $21(10.5)$ & $16(8.0)$ & $5(2.5)$ \\
Schistosoma mansoni & $9(4.5)$ & $16(8.0)$ & $1(0.5)$ \\
Strongyloides stercoralis & $2(1.0)$ & - & - \\
Trichuris trichura & - & - & $1(0.5)$ \\
\hline Total & $153(76.5)$ & $142(71.0)$ & $88(44.0)$ \\
\hline
\end{tabular}

Table 2: Stool parasites distribution according to the number of species of parasites per stool sample in Tyogbenda, Jato-Aka and Adikpo communities

\begin{tabular}{|c|c|c|c|}
\hline Species of parasites per stool sample & Distribution in the community & & \\
\hline & Tyogbenda (\%) & Jato-Aka (\%) & Adikpo (\%) \\
\hline One parasite & $136(68.0)$ & $120(60.0)$ & $88(100)$ \\
\hline Two parasites & $6(3.0)$ & $9(4.5)$ & - \\
\hline Three parasites & $1(0.5)$ & $2(1.0)$ & - \\
\hline Total & $143(71.5)^{*}$ & $131(65.5)^{* *}$ & $88(44.0)$ \\
\hline
\end{tabular}

*7 stool samples had more than one parasite; ** 11 stool samples had more than one parasite 
Table 3: Assessment of domestic methods of sewage disposal, sources of water supply and prevalence of intestinal parasites in Tyogbenda, Jato-Aka and Adikpo communities

\begin{tabular}{|c|c|c|c|c|c|c|c|}
\hline Community & $\begin{array}{l}\text { *Sewage } \\
\text { disposal system }\end{array}$ & & & $\begin{array}{l}* * \text { Source of } \\
\text { water supply }\end{array}$ & & & $\begin{array}{l}\text { Parasite } \\
\text { prevalence }\end{array}$ \\
\hline & $\begin{array}{l}\text { Water system/ } \\
\text { pit latrine }\end{array}$ & $\begin{array}{l}\text { Open air/ } \\
\text { trenches }\end{array}$ & Total & Pipe/boreholes & Wells/streams & Total & \\
\hline Tyogbenda & $73(36.5)$ & $127(63.5)$ & 200 & - & $200(100)$ & 200 & $153(76.5)$ \\
\hline Jato-Aka & $61(30.5)$ & $139(69.5)$ & 200 & $37(13.5)$ & $163(81.5)$ & 200 & $142(71.0)$ \\
\hline Adikpo & $141(70.5)$ & $59(19.5)$ & 200 & $137(68.5)$ & $63(31.5)$ & 200 & $88(44.0)$ \\
\hline
\end{tabular}

Table 4: Comparison of association between washing of hands before and after every meal and the prevalence of intestinal parasites in Tyogbenda, Jato-Aka and Adikpo communities

\begin{tabular}{|c|c|c|c|c|}
\hline Community & $\begin{array}{l}\text { Hand washing } \\
\text { response }\end{array}$ & & Total (\%) & $\begin{array}{l}\text { Parasite prevalence } \\
(\%)\end{array}$ \\
\hline & Yes $(\%)$ & No $(\%)$ & & \\
\hline Tyogbenda & $107(53.5)$ & $93(46.5)$ & $200(100)$ & $153(76.5)$ \\
\hline Jato-Aka & $98(49.0)$ & $102(51.0)$ & $200(100)$ & $142(71.0)$ \\
\hline Adikpo & $173(86.5)$ & $27(13.5)$ & $200(100)$ & $88(44.0)$ \\
\hline
\end{tabular}

$\mathrm{X}^{2}=32.61, \mathrm{OR}=0.35, \mathrm{RR}=0.62, \mathrm{p}<0.0001$

\section{Discussion}

Of the 200 subjects studied in each locality, the prevalence of intestinal parasites was found to be $76.5 \%$ in Tyogbenda, $71.0 \%$ in Jato-Aka, and $44.0 \%$ in Adikpo. These findings are much higher than that of Ogbonna et $\mathrm{al}^{6}$ in Jos where a prevalence of $33.2 \%$ was found. The urban nature of the previous study and consequent availability of basic amenities such as pipe borne water and improved sewage disposal facilities could account for the lower figure. On the other hand Tyogbenda and Jato-Aka, lack these facilities, hence the high prevalence recorded in them. On the contrary, Adikpo, with improved quality of water supply and sewage disposal facilities recorded a much lower figure compared to the other two communities in the present study.

The findings from this study however agree with that of Salako in Lagos $^{5}$ in a locality with similar infrastructural facilities. Similar findings were also recorded by Araujo et $\mathrm{al}^{7}$ and Ferreire et $\mathrm{al}^{8}$ both in Brazil and Blangs et $\mathrm{al}^{9}$ in Indonesia. Also findings from Papua New Guinea ${ }^{10}$ compares favourably with this present study. The findings from this study and similar findings from other parts of the world further confirms the fact that intestinal parasitism is still of global public health importance.

Although findings from the present study have further proven that, the United Nations declaration of $1981-1990$ as the International drinking water supply and sanitation decade has failed to realize its goals 15 years thereafter! This can however be realized in the new millennium if the global community revisits this issue with renewed vigour and special programs designed to accommodate the weaker nations of the earth.

The improvement in quality of water supply and methods of sewage disposal had dramatic impact on the prevalence of multiple intestinal parasitic infestations in Adikpo as compared to Tyogbenda and Jato-Aka. This pattern was similarly reported by Kelly et al. ${ }^{11}$ The association between regular hand washing and intestinal parasitism was found to be highly significant in the present study. The low prevalence of intestinal parasites in Adikpo community where majority of the people wash hands as compared to the other communities is quite obvious. Hand washing has long been established to have a significant impact on the spread of several infections. ${ }^{7,12-14}$

If the adoption of the culture of regular hand washing is entrenched in our communities along with improvement in the quality of water supply and methods of sewage disposal facilities; the level of intestinal parasites and other diseases with similar modes of transmission will fall drastically. A recent report from the Federal Ministry of Water resources ${ }^{15}$ is said to have covered $60 \%$ of the Nigerian population with potable water, with a further desire to cover about $80 \%$ of the population by the end of 2006. As cheering as this news is, we still call on the federal ministry of water resources to double her efforts as there are many communities lacking these facilities at present. The success of this program will no doubt reduce the prevalence of intestinal parasites in our communities.

Considering the role provision of quality water contributes towards elimination of parasites and other infectious agents. Health education should be tied to provision of potable water and locally acceptable methods of purifying water like boiling should be emphasized. This education should include proper management of sewage at the community level and should discourage open air defaecation and use of trenches.

Health resource persons could be recruited from within the communities and should be conversant 
with the norms and traditions of the people to blend smoothly and have a successful health education.

\section{Conclusion}

The prevalence of intestinal parasites is still high in our communities. The contributory factors include; lack of potable water availability, lack of appropriate sewage disposal facilities and regular hand washing. We therefore call on the Federal government through the Ministry of water resources to sustain her present momentum towards provision of potable water to every Nigerian. In addition, the deployment of health educators to all our Primary Health Centres (PHCs) and Comprehensive Health Centres (CHCs) to sustain public enlightenment at community level could be considered as an adjunct to further strengthen our present Primary health care policy in the country. Finally, mass chemotherapy with broad spectrum antihelminths may drastically reduce the parasite load of the rural populace, the financial implications not withstanding, as it really may not be a waste of resources by the government.

\section{Acknowledgement}

The authors wish to thank most sincerely the following- the Chairman, Kwande Local Government Area, Management and staff of government CHCs at Adikpo and Jato-Aka and finally, N.K.S.T Comprehensive health centre Aku for all their assistance towards the successful completion of this work.

\section{References}

1. van Nostrand J, Wilson JG. Rural ventilated improved pit latrines. A joint contribution of the government of Botswana, the UNDP and the World bank to International Water Supply and Sanitation Decade. TAG Technical Note 1983; No 8

2. Compton DWT, Savioli L. Intestinal parasitic infection and urbanization. Bull WHO 1993; 71: $1-7$

3. Odutan SO. Medical care for the Nigerian school child. Nigerian Medical Journal 1973; 3: 116-119

4. Okpala I. The incidence of intestinal parasites among school children in Lagos. (Nigeria). West Afr Med J 1956; 5: 16-17

5. Salako AA. Effects of potable water availability on intestinal parasitism among rural school children with sewage disposal facilities in the Majidun and Owutu sub-urban community in Lagos state. Nigerian Medical Practitioner 2001;39: 30-35

6. Ogbonna SN, Okolo MC, Okonji PL. Intestinal worms and nutritional status of under fives in Jos, Nigeria: Any relationship? Niger J Clin Pract 2004; 7:79-81

7. Araujo CF, Fernandez CL. Prevalence of intestinal parasites in the city of Eirunepe, Amazon. Rev Soc Brasil Med Trop 2005; 38: 69

8. Ferreira P, Lima MR, Oliveira FB, et al. Occurrence of intestinal parasites and commensal organisms among school children living in a landless farm workers settlement in Campo Florido, Minas Gerais state, Brazil. Rev Soc Brasil Med Trop 2003; 36: 109-111

9. Blangs MJ, Purnomo EM, Anderson N, Anthony RT. Intestinal parasites of humans in a highland community of Irian, Jaya, Indonesia. Ann Trop Med Parasitol 1996; 90: 40-43

10. Ashford RN, Halt AJ, Babona D. Distribution and abundance of intestinal helminths in man in western Papua New Guinea with special reference to strongyloides. Ann Trop Med Parasitol 1981; 75: 269- 279

11. Kelly A, Gar Avusi MA. Parasitological survey of a village in a mountain district of Papua. Trop Geo Med 1974; 26: 178- 181

12. Health Canada. Routine practices and additional precautions for preventing transmission of infection in health care. Can Commun Dis Rep 1999; 25(suppl.4): 1- 142

13. Ducel G. Practical guide to prevention of hospital acquired infections. 1974; WHO/BAL/79.1.

14. Pratt RJ. The epic project. Developing national evidence- based guidelines for preventing healthcare associated infections phase I. Guidelines for preventing hospital acquired infections. J Hosp Infect 2001; 47(suppl.): S3- S4

15. Nigerian Television Authority (NTA), Saturday AM plus. Report from Federal Ministry of Water Resources. 2005; July 2nd 